\title{
Two new species of the pseudoscorpion genus Lagynochthonius from China (Pseudoscorpiones: Chthoniidae)
}

\author{
Fubin Zhang \& Feng Zhang*
}

\begin{abstract}
Zhang, F. \& Zhang, F. 2014: Two new species of the pseudoscorpion genus Lagynochthonius from China (Pseudoscorpiones: Chthoniidae). - Entomol. Fennica 25: 170-179.

Two new pseudoscrorpion species belonging to the genus Lagynochthonius of the family Chthoniidae are described from China: Lagynochthonius brachydigitatus sp. n., from Zhejiang Province, and L. medog sp. n., from Xizang Autonomous Region. Lagynochthonius microdentatus Hu \& Zhang, 2012 is found to be a junior primary homonym of L. microdentatus Mahnert, 2011 and is replaced with Lagynochthonius harveyi Hu \& Zhang, nom. n.

F. Zhang \& F. Zhang*, The Key Laboratory of Invertebrate Systematics and Application, College of Life Sciences, Hebei University, Baoding, Hebei 071002, P. R. China; E-mail: 15131259861@163.com, *Corresponding author: dudu06042001@163.com
\end{abstract}

Received 22 April 2014, accepted 19 July 2014

\section{Introduction}

The arachnid order Pseudoscorpiones is a cosmopolitan group of small arthropods mainly occurring in leaf litter, under rocks and stones, or within caves. There are 26 families currently recognized, including 3,533 species in 454 genera (Harvey 2013). Chthoniidae, currently containing 28 genera and 650 species worldwide, is the second-most speciose family in the order. To date, only two genera (Lagynochthonius Beier, 1951, and Tyrannochthonius Chamberlin, 1929) of the tribe Tyrannochthoniini have been recorded from China (Harvey 2013).

The genus Lagynochthonius was erected by Beier (1951) as a subgenus of Tyrannochthonius Chamberlin, but Chamberlin (1962) later elevated it to generic status. The genus is characterized by the flask-shaped chelal hand, the greatly enlarged sclerotic apodeme of the movable finger and the modified tooth (or distal tooth) of fixed chelal finger displaced onto the dorso-antiaxial face (Judson 2007).

While examining pseudoscorpion specimens collected from Jiulong Mountains (Zhejiang Province) and Medog County (Xizang Autonomous Region) in China, we found two new species of Lagynochthonius, which we here name L. brachydigitatus sp. n. and $L$. medog sp. n. We also provide the replacement name Lagynochthonius harveyi $\mathrm{Hu} \&$ Zhang, nom. n. for Lagynochthonius microdentatus Hu \& Zhang, 2012.

\section{Material and methods}

The terminology used in this paper follows Chamberlin (1931), Harvey (1992) and Judson (2007). The setal formula of the palp femur follows Vachon (1941) (rows in sequence anterioranterodorsal-dorsal-posterodorsal-posteriorventral). All specimens are preserved in $75 \%$ al- 
Fig. 1. Habitus of Lagynochthonius brachydigitatus sp. n., dorsal view. - a. Holotype male. - b. Paratype female.

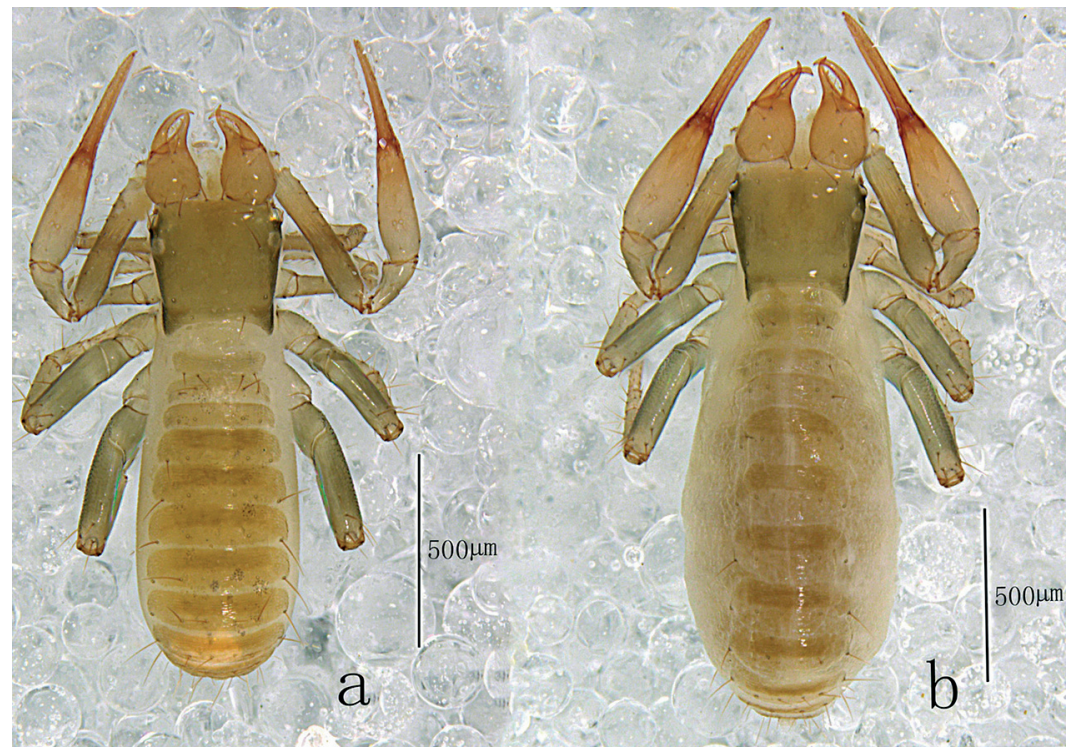

cohol, and they were examined and illustrated using a Leica 205A stereomicroscope with a drawing tube, which was also used for the measurements.

Detailed examination was carried out with an Olympus BX53 general optical microscope. Temporary slide mounts were made in glycerol. All measurements are given in millimetres. The type specimens are deposited in the Museum of Hebei University (MHBU), Baoding City, China.

The following abbreviations are used in the text for the trichobothria: $b=$ basal; $s b=$ subbasal; $s t=$ sub-terminal; $t=$ terminal; $i b=$ interior basal; is $b=$ interior sub-basal; ist = interior subterminal; $i t=$ interior terminal; $e b=$ exterior basal; $e s b=$ exterior sub-basal; $e s t=$ exterior subterminal; et $=$ exterior terminal; $d x=$ duplex trichobothria. Carapacal chaetotaxy is expressed in the form 6-2 (18), where 18 refers to the total number of setae, 6 the number on the anterior margin and 2 the number on the posterior margin.

\section{Genus Lagynochthonius Beier, 1951}

Lagynochthonius Beier, 1951: 61; Chamberlin, 1962: 314; Judson, 2007: 53-68; Mahnert, 2011: 33-38; Muchmore, 1991: 113; Harvey, 1999: 247; Edward \& Harvey, 2008: 280; Hu \& Zhang, 2011: 223-232; Hu \& Zhang, 2012: 21-25.

\subsection{Lagynochthonius harveyi Hu \& Zhang, nom. n.}

$\mathrm{Hu} \&$ Zhang (2012) published a new Lagynochthonius species (collected from Yunnan Province, China) which was named $L$. microdentatus, but, unfortunately, the same name had been used by Mahnert (2011) for a different Lagynochthonius species (collected from the Canary Islands, Spain). Mark Harvey (personal communication, 2013) pointed out to us that Lagynochthonius microdentatus $\mathrm{Hu} \&$ Zhang, 2012 is a junior primary homonym of Lagynochthonius microdentatus Mahnert, 2011. Therefore, we here provide the replacement name Lagynochthonius harveyi $\mathrm{Hu} \&$ Zhang, nom. n. for Lagynochthonius microdentatus $\mathrm{Hu} \&$ Zhang, 2012.

\subsection{Descriptions of new species}

\subsubsection{Lagynochthonius brachydigitatus $\mathbf{s p .} \mathbf{n}$. (Figs. 1-3)}

Type material. Holotype male (Ps.-MHBUZJ13070401): China, Zhejiang Province, Suichang County, Jiulong Mountains, Yanping [28 ${ }^{\circ} 22^{\prime} \mathrm{N}, 118^{\circ} 53^{\prime} \mathrm{E}$ ], alt. $868 \mathrm{~m}, 4 . \mathrm{VII} .2013$, Fubin Zhang leg. Paratypes: four males (Ps.MHBU-ZJ13070402-05) and five females (Ps.- 


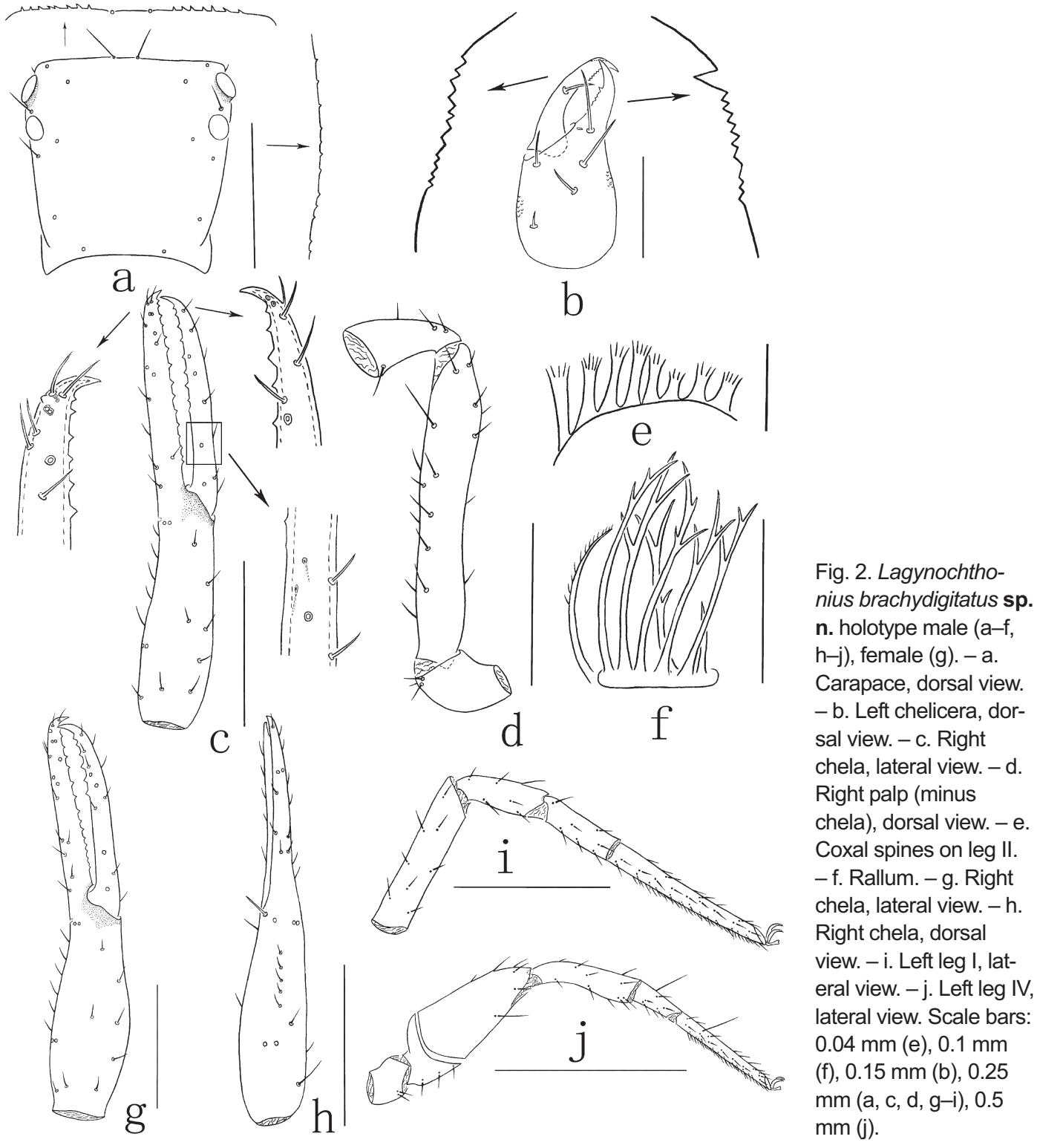

MHBU-ZJ13070406-10), same data as for holotype.

Diagnosis. Lagynochthonius brachydigitatus is characterized by the following combination of characters: medium sized (body length male $1.16-1.26 \mathrm{~mm}$, female $1.58-1.59 \mathrm{~mm}$ ); carapace without epistome; anterior pair of eyes well developed, posterior pair of eyes reduced to eyespots; chelal fingers without intercalary teeth; $e b$-esb-ist nearly in straight line; male pedipalpal femur 5.75 (female 5.50-6.00) times longer than broad; male chela 5.82-6.20 (female 4.88-5.00) times longer than broad; male movable finger 1.03 (female $0.97-1.00$ ) times longer than hand.

Description. Male. Colouration: Carapace, abdomen, pedipalpal femur and legs moderately olive-brown, other parts yellowish (Fig. 1a).

Carapace (Figs. 2a, 3b): Subquadrate, somewhat longer than broad, constricted posteriorly; nearly smooth, but anterior margin denticulate, posterior part with squamous sculpturing; anterior pair of eyes well developed, the posterior 


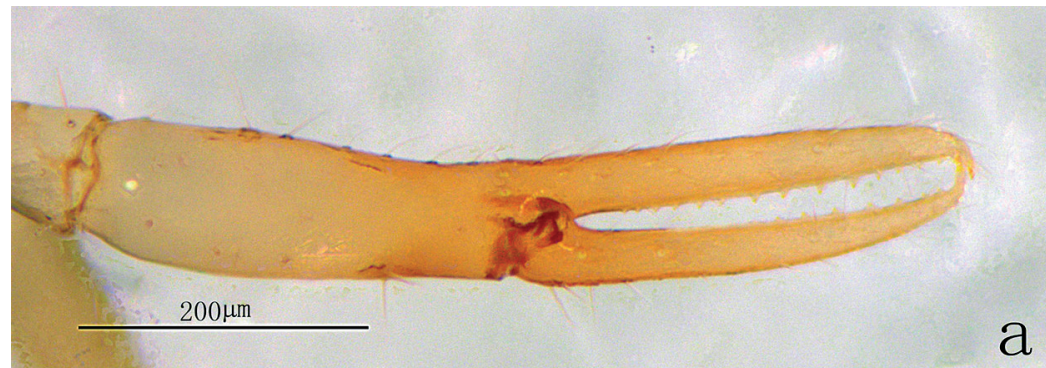

Fig. 3. Lagynochthonius brachydigitatus sp. n. holotype male $(\mathrm{a}-\mathrm{d}$, $f, g)$, female (d). $-a$. Right chela, lateral view. - b. Carapace, dorsal view. - c. Left chelicera, dorsal view. - d. Genital area of male. - e. Genital area of female. $-f$. Left leg I, lateral view. $-\mathrm{g}$. Left leg IV, lateral view.
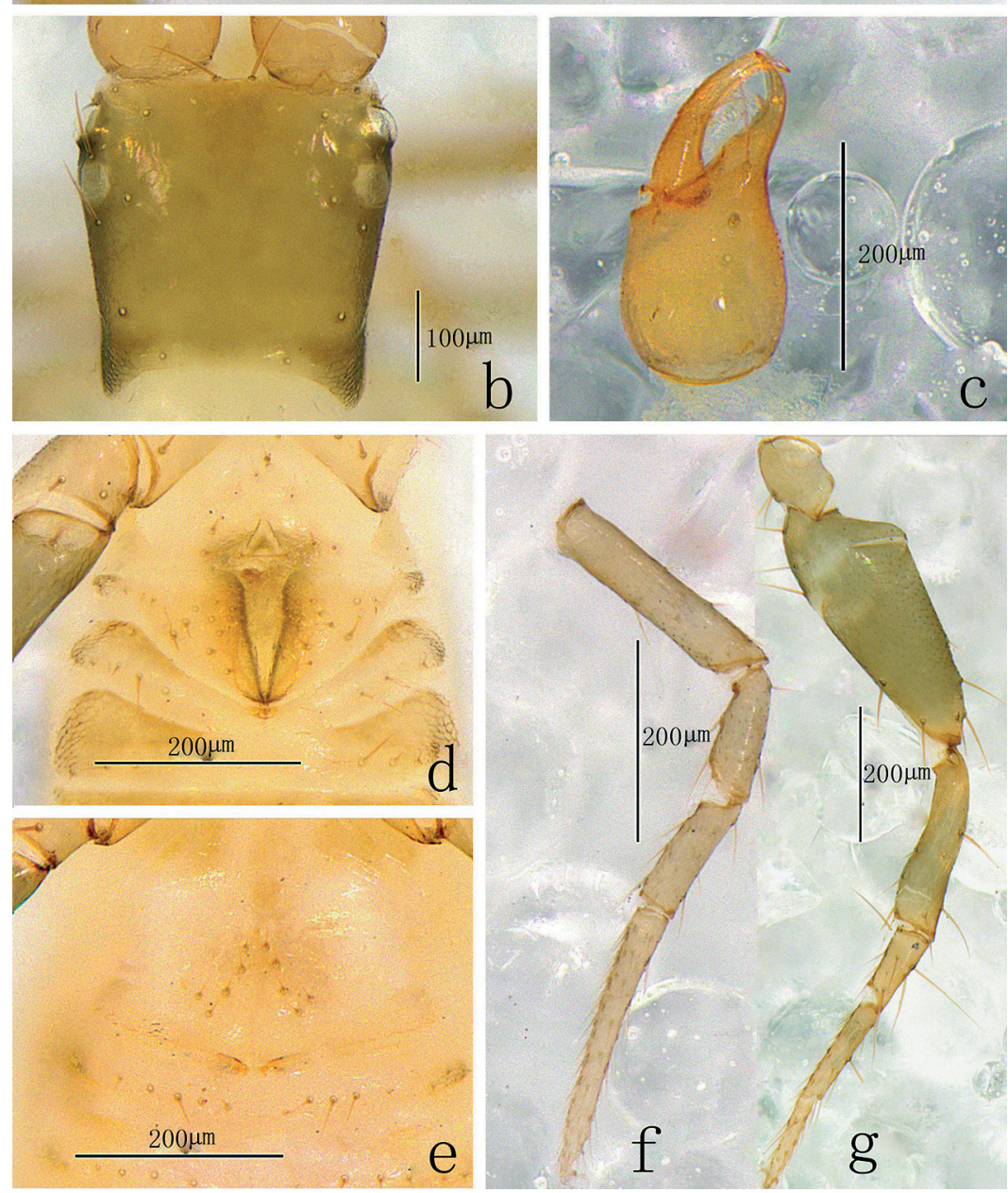

ones rudimentary, merely lighter spots; eyes almost one diameter from each other, anterior pair of eyes $1 / 2$ diameter from the anterior margin of the carapace; epistome absent, space between median setae weakly depressed; carapacal chaetotaxy: m4m-2 (18), including 16 long setae and 2 preocular microsetae.

Coxal area: Of usual facies; manducatory process with 2 distal setae, one long and the other slightly shorter. Intercoxal tubercle absent; coxa I with a short, lateral, finger-like projection; coxa II with 8 distally incised spines arranged in oblique row (Fig. 2e); setae P 5, I 3, II 3-4, III 5, IV 5.

Chelicera (Figs. 2b, 3c): Distinctly shorter than carapace; hand with 5 setae, $b s$ short, galeal seta located in middle of movable finger; hand with tiny granulation laterally. Fixed finger with 8-10 conspicuous teeth, the apical one large and 
others small; movable finger with 9-11 acute, conspicuous teeth; one lyrifissure at base of fixed finger; spinneret flattened and broad, larger and more distinct in female than in male. Serrula exterior with 15 lamellae; serrula interior with 10 lamellae. Rallum composed of 8 blades, distal blade recumbent basally, with fine barbules and set apart from others, latter tightly grouped and with long pinnae, some of which are divided, the basal one shorter than the others (Fig. 2f).

Pedipalp (Figs. 2c, 2h, 3a): Palpal femur setal formula 5-5-1-3-4-0; chelal hand elongate and constricted distally, dorsal surface of hand with a single row of 4 chemosensory setae between trichobothria esb and $i b / i s b$; a short spine-like seta near the base of fixed finger. Fixed finger with 15 well-spaced pointed teeth, without intercalary teeth; movable finger with 8-9 wellspaced pointed teeth (reaching midway between $b$ and $s b$ ), without intercalary teeth; fixed finger with a modified accessory tooth on dorsoantiaxial face (Fig. 2c), between the sensilla of and trichobothria $d x$; fixed finger with 2 sensilla af $1-2$ close together, near tip. Movable finger with 4 sensilla: $a m_{1-2}$ near tip; $p_{1-2}$ just in front of trichobothrium $s b$; terminal tooth of movable finger not appearing hooked; apodeme complex of movable finger strongly sclerotized. Trichobothria: fixed finger with eight and movable finger with four; in addition, two special trichobothria $(d x)$ present, located near the tip of fixed finger; $s b$ of movable finger twice times as far from $s t$ as from $b$; $e b$-esb-ist nearly in straight line near base of fixed finger.

Abdomen: Ovate, pleural membrane papillostriate; tergites and sternites undivided, tergal chaetotaxy I-XII: 4: 4: 4: 5: 5: 5-6: 6: 6: 6: 4: T2T : 0 ; anterior operculum with 9-10 setae, genital opening slit-like in basal half, each side with 9-11 marginal setae, 18-21 in total; sternal chaetotaxy III-XII: 13-14: 10-11: 11: 10-12: 12: 11: 10-11: 9: -: 2.

Legs I (Figs. 2i, 3f) and IV (Figs. 2j, 3g): Typical. Femur and patella of leg IV with fine granulation. Leg IV with a long tactile seta on both basitarsus (TS=0.40) and telotarsus ( $\mathrm{TS}=0.26$ ).

Female. Generally similar to male, but a little larger and with chelal hand more robust (Figs. 1b, $2 \mathrm{~g}$ ).

Tergal chaetotaxy I-XII: $4: 4: 4: 4-5: 6: 6: 5-$
6: 6: 6: 4: T2T: 0 ; anterior genital operculum with 10 setae and 12 setae along posterior margin, 22 in total; sternal chaetotaxy III-XII: 12-13: 11: 11: 11: 11: 11-12: 9: 10: -: 2.

Measurements (length/breadth or, for legs, length/depth in $\mathrm{mm}$, ratios in parentheses). Male (holotype and paratype). Body length 1.16-1.26. Carapace 0.32-0.35×0.31-0.34 (1.03). Chelicera $0.29 \times 0.15$ (1.93), movable finger length 0.16 . Palpal trochanter $0.14-0.15 \times 0.08(1.75-1.88)$, femur $0.46 \times 0.08$ (5.75), patella $0.17-0.18 \times 0.08$ (2.13-2.25), chela $0.62-0.64 \times 0.10-0.11(5.82$ $6.20)$, hand $0.30-0.31 \times 0.10-0.11(2.73-2.82)$, movable finger length $0.31-0.32$ ( $1.03 \times$ hand $)$. Leg I trochanter $0.10 \times 0.08$ (1.25), femur $0.25 \times 0.05-0.06(4.17-5.00)$, patella $0.14 \times 0.05$ (2.80), tibia $0.12-0.14 \times 0.04(3.00-3.50)$, tarsus $0.28-0.29 \times 0.03(9.33-9.67)$; leg IV trochanter $0.14 \times 0.09-0.10 \quad(1.40-1.56), \quad$ femur + patella $0.42-0.44 \times 0.17-0.18 \quad(2.33-2.59), \quad$ tibia $0.28 \times 0.06-0.07 \quad(4.00-4.67), \quad$ basitarsus $0.13 \times 0.05$ (2.60), telotarsus $0.31 \times 0.04$ (7.75).

Female (paratypes). Body length 1.58-1.59. Carapace $0.37-0.40 \times 0.38-0.42 \quad(0.95-0.97)$. Chelicera $\quad 0.34-0.37 \times 0.17-0.18 \quad(2.00-2.06)$, movable finger length $0.20-0.21$. Palpal trochanter $0.15 \times 0.11$ (1.36), femur $0.55-0.60 \times 0.10$ (5.50-6.00), patella $0.21-0.22 \times 0.11(1.91-2.00)$, chela $0.75-0.83 \times 0.15-0.17(4.88-5.00)$, hand $0.38-0.42 \times 0.15-0.17(2.47-2.53)$, movable finger length $0.37-0.42(0.97-1.00 \times$ hand $)$. Leg I trochanter $0.10-0.11 \times 0.08-0.09(1.22-1.25)$, femur $0.28-0.32 \times 0.06-0.07$ (4.57-4.67), patella $0.16-0.17 \times 0.05-0.06(2.83-3.20)$, tibia 0.15 $0.17 \times 0.04-0.05 \quad(3.40-3.75)$, tarsus $0.33-$ $0.35 \times 0.04(8.25-8.75)$; leg IV trochanter 0.15 $0.17 \times 0.10-0.11 \quad(1.50-1.55), \quad$ femur+patella $0.47-0.51 \times 0.19-0.20(2.47-2.55)$, tibia 0.32 $0.35 \times 0.07-0.08 \quad(4.38-4.57), \quad$ basitarsus $0.15 \times 0.06(2.50)$, telotarsus $0.36-0.38 \times 0.04$ (9.00-9.50).

Distribution. This species has only been found in Zhejiang Province, China.

Etymology. The specific name is derived from the Latinized combination form of Greek brakhys and Latin word "digitatus", meaning short finger.

Remarks. Previously, five Lagynochthonius species have been recorded from China: $L$. tonkinensis (Beier, 1951), L. sinensis (Beier, 1967), L. niger Hu \& Zhang, 2011, L. leptopalpus 
Fig. 4. Habitus of Lagynochthonius medog sp. n., dorsal view. - a. Holotype male. - b. Paratype female.

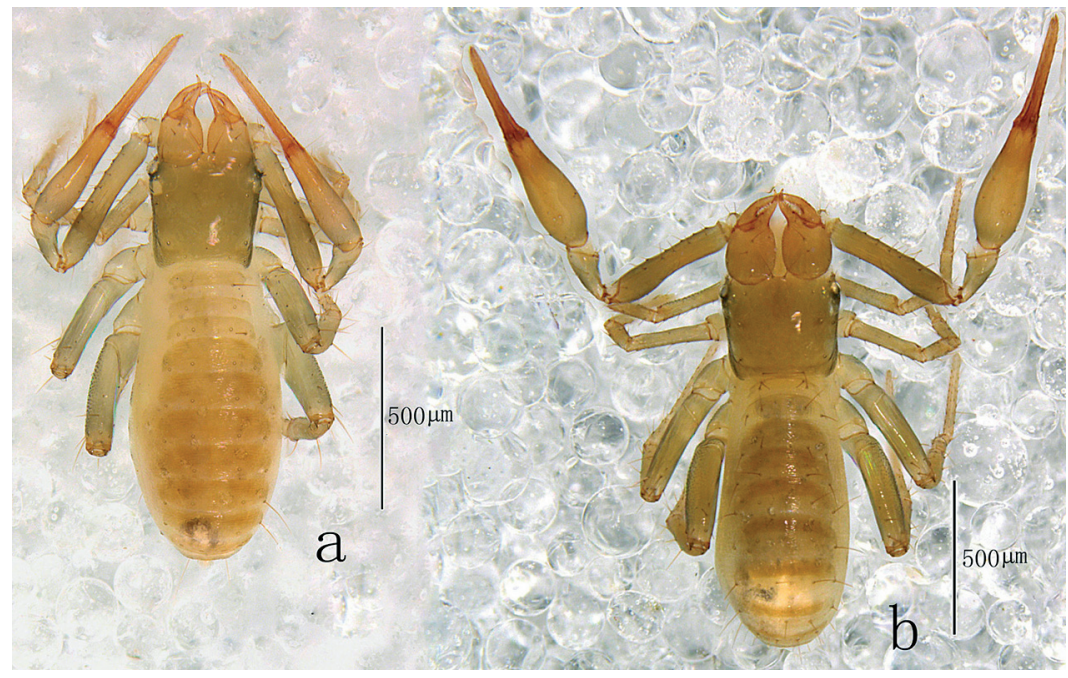

$\mathrm{Hu} \&$ Zhang, 2011. Lagynochthonius harveyi $\mathrm{Hu}$ \& Zhang, nom. nov. Lagynochthonius brachydigitatus sp. n. can be readily separated from these species by the identification key provided below.

Several other Lagynochthonius species from Asia, namely L. paucedentatus (Beier, 1955) from Malaysia, L. thorntoni Harvey, 1988 from Indonesia and L. brincki (Beier, 1973) from Sri Lanka, are similar to the new species in having the movable chelal finger approximately the same length as the hand. However, L. brincki differs from the new species by the presence of a small epistome and the number of coxal spines on coxa II (5 vs. 10); L. paucedentatus differs from the new species by the larger body size $(2.00$ $v s .1 .16-1.26)$ and by having fewer teeth on fixed chelal finger (12vs. 15); L. thorntoni has intercalary teeth on the chela fingers, whereas the new species lacks them. Finally, the new species resembles L. australicus (Beier, 1966), from Australia; in having trichobothria eb-esb-ist nearly in a straight line at the base of the fixed finger, but it is distinguished from the latter by lacking intercalary teeth on the fixed chelal finger (present in L. australicus) and the absence of an epistome (a small epistome is present in L. australicus).

\subsubsection{Lagynochthonius medog sp. $\mathbf{n}$.}

(Figs. 4-6)

Type material. Holotype male (Ps.-MHBUXZ13092011); China, Xizang Autonomous Re- gion, Medog County [29¹9’ N, 95²0’ E], alt. 1,209 m, 20.IX.2013, Zhizhong Gao leg. Paratypes: seven males (Ps.-MHBU-XZ13092012-18) and two females (Ps.-MHBU-XZ13092019-20), same data as for holotype.

Diagnosis. Lagynochthonius medog sp. n. is characterized by the following combination of characters: carapace with four corneate eyes; epistome absent; chelal fingers with intercalary teeth; male pedipalpal femur 5.88-6.13 (female 6.44) times longer than broad; male chela 6.90 7.22 (female 5.50-6.00) times longer than broad; and male movable finger 1.06-1.09 (female 1.00) times longer than hand.

Description. Male. Colouration: Carapace, pedipalpal femur, hand and legs moderately olive-brown, other parts yellowish (Fig. 4a).

Carapace (Figs. 5a, 6b): Subquadrate, weakly constricted basally; nearly smooth, but with anterior margin denticulate, posterior region with squamous sculpturing; anterior pair of eyes welldeveloped, posterior pair with lenses; epistome absent, middle region weakly depressed; eyes almost $1 / 2$ diameter from each other, anterior pair of eyes $1 / 2$ diameter from the anterior margin of the carapace; carapacal chaetotaxy: m4m-2 (18), including 16 long setae and 2 preocular microsetae.

Coxal area (Fig. 5g): Manducatory process with 2 distal setae, one long and the other slightly shorter. Intercoxal tubercle absent; coxa I with a short, lateral, finger-like projection, coxa II with 


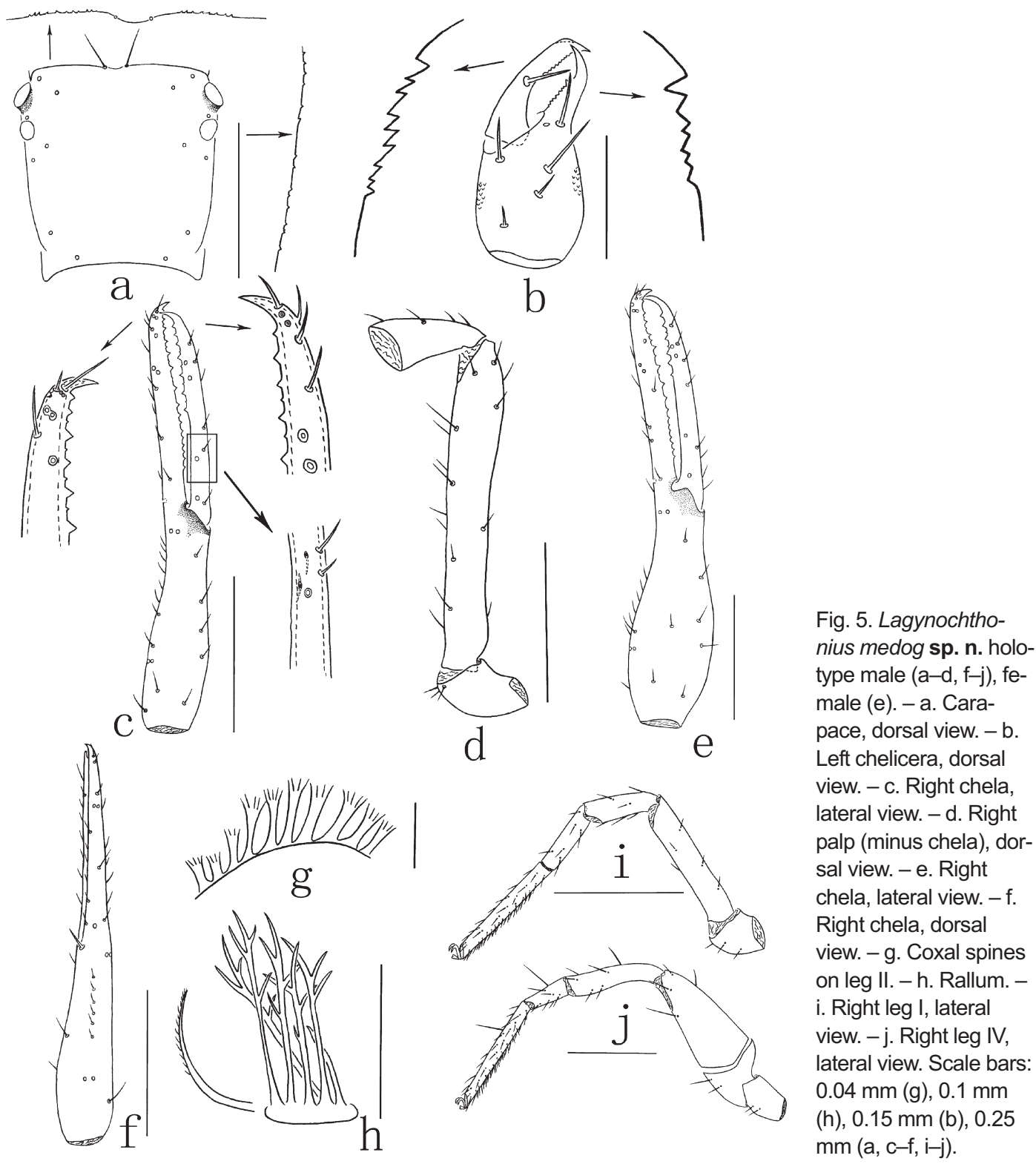

10 distally incised spines arranged in oblique row; setae P 5, I 3, II 4, III 5, IV 5.

Chelicera (Figs. 5b, 6c): Hand with 5 setae; galeal seta located medially on movable finger; hand with tiny granulation laterally. Fixed finger with 6 conspicuous teeth, apical tooth large and others small; movable finger with 9 acute, slightly retrorse teeth; one lyrifissure at base of fixed finger; spinneret broad, flattened and transparent. Serrula exterior with 18 lamellae; serrula interior with 12 lamellae. Rallum composed of 7 blades, distal blade recumbent basally, with fine barbules and set apart from others, latter tightly grouped and with long pinnae, some of which are divided, the basal blade shorter than others (Fig. 5h).

Pedipalp (Figs. 5c, 5f, 6a): Slender; palpal femur setal formula 5-4-1-3-4-0; movable finger finger 1.06-1.09× longer than hand length; dorsal surface of hand with a single row of 6 chemosensory setae between trichobothria esb and $i b / i s b$; a short, spine-like seta near base of fixed 


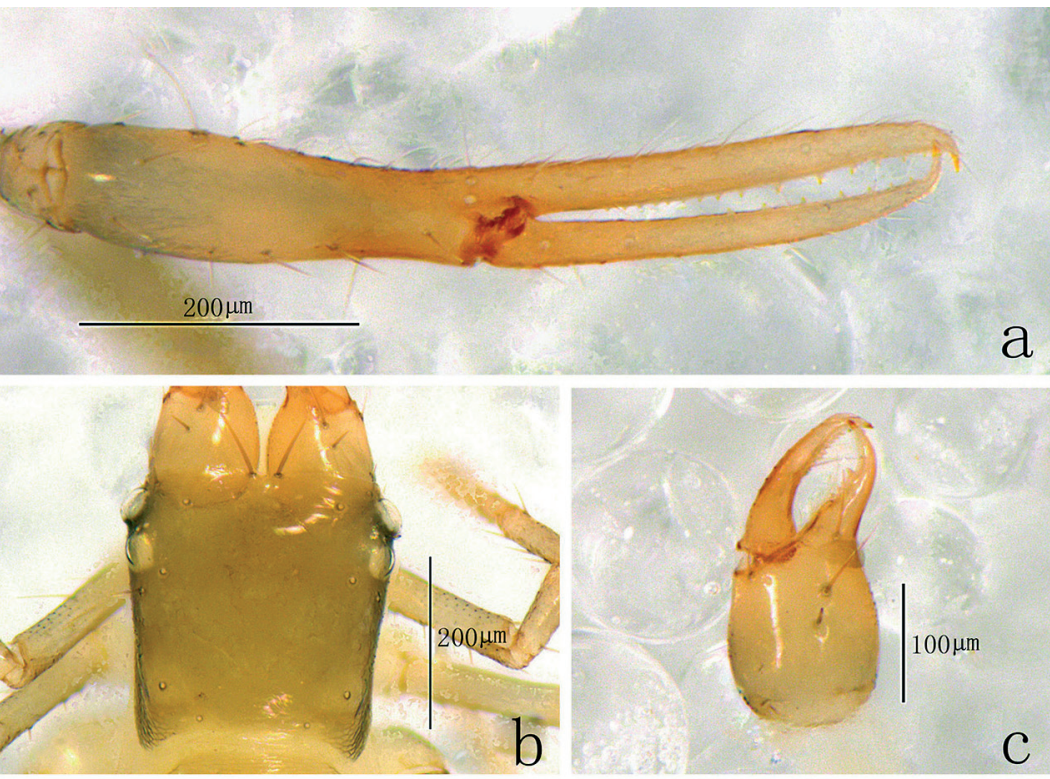

Fig. 6. Lagynochthonius medog sp. $\mathbf{n}$. holotype male $(\mathrm{a}-\mathrm{f})$, female (g). - a. Right chela, lateral view. - b. Carapace, dorsal view. - c. Left chelicera, dorsal view. - d. Right leg I, lateral view. - e. Right leg IV, lateral view. $-\mathrm{f}$. Genital area of male. - g. Genital area of female.
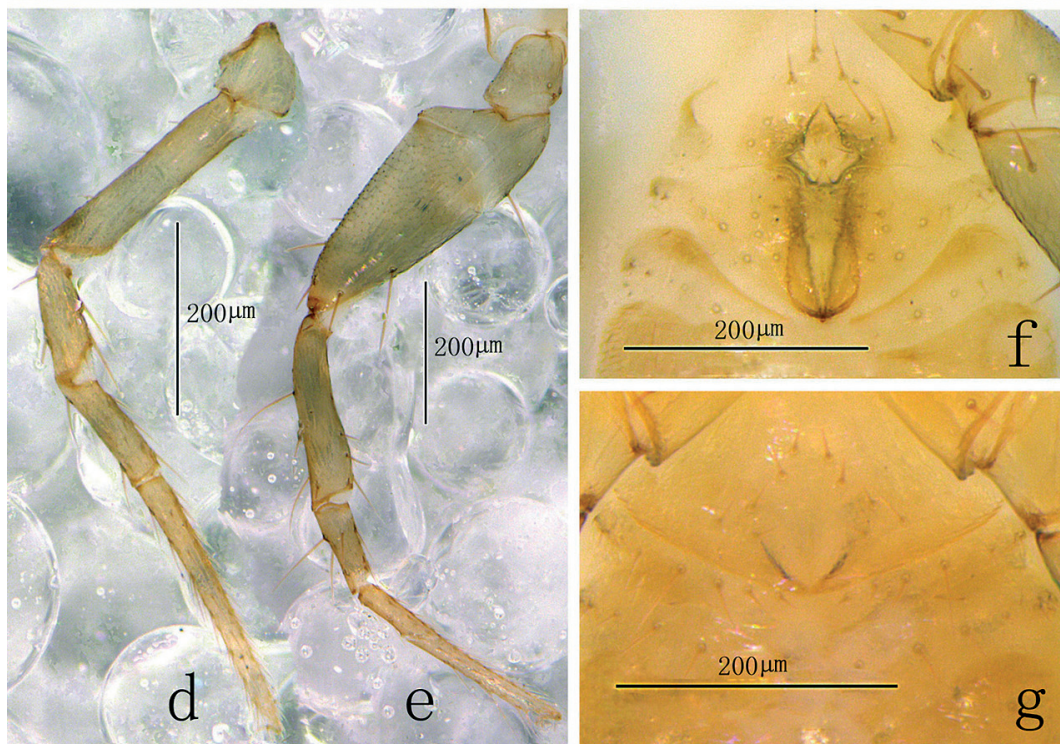

finger. Fixed finger with 15-16 well-spaced, pointed teeth and 5-6 tiny intercalary teeth in distal part; movable finger with 7 well-spaced, pointed teeth (reaching midway between $b$ and $s b$ ) and 4 tiny intercalary teeth; tip of fixed finger with a modified accessory tooth on dorsoantiaxial face, situated slightly distal to $d x$ (Fig. $5 \mathrm{c}$ ); fixed finger with 2 sensilla $a f_{1-2}$ close together, near tip. Movable finger with 4 sensilla: $a m_{1-2}$ near tip; $p_{1-2}$ just in front of trichobothrium $s b$; terminal tooth of movable finger not appearing hooked; apodeme complex of movable finger strongly sclerotized. Trichobothria: fixed finger with eight and movable finger with four; in addition, two special trichobothrium $(d x)$ present, located near the tip of fixed finger; $s b$ of movable finger twice times as far from $s t$ as from $b$, ist almost level with $e b$-esb.

Abdomen: Ovate, pleural membrane papillostriate; tergites and sternites undivided, tergal chaetotaxy I-XII: $2: 2: 4: 4: 4: 4-5: 4: 5: 4-5: 4$ : T2T: 0; anterior genital operculum with $8-10$ setae, genital opening slit-like in the basal half, each side with 10 marginal setae, $18-20$ in total; 
sternal chaetotaxy III-XII: 10-12: 10-12: 9-10: 9-10: 8-9: 8-9: 8: 9 : -: 2.

Legs I (Figs. 5i, 6d) and IV (Figs. 5j, 6e): Typical. Femur and patella of leg IV with fine granulation. Leg IV with a long tactile seta on both basitarsus $(\mathrm{TS}=0.30)$ and telotarsus $(\mathrm{TS}=0.28$ 0.29).

Female. Generally similar to male, but a little larger (Figs. 4b, 5e).

Tergal chaetotaxy I-XII: $2: 2: 4: 4: 4: 5: 5: 5-$ 6: 5: 4-5: T2T: 0 ; anterior genital operculum with 10 setae, posterior margin with 11 marginal setae, 21 in total; sternal chaetotaxy III-XII: 11: 11: 10: 9: 9: 9: 9: $10:-: 2$.

Measurements (length/breadth or, for legs, length/depth in $\mathrm{mm}$, ratios in parentheses). Male (holotype and paratype). Body length 1.08-1.14. Carapace $0.31 \times 0.30-0.31(1.00-1.03)$. Chelicera $0.26-0.27 \times 0.13(2.00-2.08)$, movable finger length 0.14 . Palpal trochanter $0.14-0.15 \times 0.08$ (1.75-1.88), femur 0.47-0.49×0.08 (5.88-6.13), patella $0.14-0.17 \times 0.08(1.75-2.13)$, chela $0.65-$ $0.69 \times 0.09-0.10 \quad(6.90-7.22)$, hand $0.31-0.32$ $\times 0.09-0.10(3.20-3.44)$, movable finger length $0.33-0.35$ (1.06-1.09 $\times$ hand). Leg I trochanter $0.09-0.10 \times 0.08 \quad(1.13-1.25)$, femur $0.26-$ $0.27 \times 0.05(5.20-5.40)$, patella $0.13-0.14 \times 0.04$ $0.05(2.60-3.50)$, tibia $0.13-0.14 \times 0.04(3.25-$ $3.50)$, tarsus $0.30-0.31 \times 0.03(10.00-10.33)$; leg IV trochanter $0.13-0.15 \times 0.09$ (1.44-1.67), femur+patella $0.43-0.45 \times 0.17-0.18(2.50-2.53)$, tibia $0.26-0.28 \times 0.06 \quad(4.33-4.67)$, basitarsus $0.13-0.14 \times 0.05(2.60-2.80)$, telotarsus $0.32-$ $0.35 \times 0.03(10.67-11.67)$.

Female (paratypes). Body length 1.21-1.35. Carapace $0.34-0.36 \times 0.36-0.38 \quad(0.94-0.95)$. Chelicera $\quad 0.30-0.33 \times 0.15-0.16 \quad(2.00-2.06)$, movable finger length 0.16 . Palpal trochanter $0.15-0.16 \times 0.10-0.11(1.45-1.50)$, femur $0.58-$ $0.60 \times 0.09-0.10 \quad(6.00-6.44)$, patella $0.17-$ $0.18 \times 0.11(1.55-1.64)$, chela $0.77-0.80 \times 0.14$ 0.15 (5.50-6.00), hand $0.38-0.41 \times 0.14-0.15$ (2.71-2.73), movable finger length $0.38-0.41$ $(1.00 \times$ hand $)$. Leg I trochanter $0.10-0.11 \times 0.09$ (1.11-1.22), femur 0.28-0.30×0.05-0.06 (4.67$6.00)$, patella $0.15-0.16 \times 0.05(3.00-3.20)$, tibia $0.14-0.16 \times 0.04 \quad(3.50-4.00)$, tarsus 0.32 $0.33 \times 0.04(8.00-8.25)$; leg IV trochanter $0.15-$ $0.16 \times 0.10 \quad(1.50-1.60)$, femur+patella $0.46-$ $0.50 \times 0.17-0.19 \quad(2.63-2.71)$, tibia $0.32-$
$0.33 \times 0.07(4.57-4.71)$, basitarsus $0.15 \times 0.05$ $0.06(2.50-3.00)$, telotarsus $0.35-0.38 \times 0.04$ (8.75-9.50).

Distribution. This species has only been found in the Xizang Autonomous Region, China.

Etymology. The specific name refers to the type locality, and is to be treated as a noun in apposition.

Remarks. The other species of the genus of comparable size and with such a slender chela are L. johni (Redikorzev, 1922) and L. roeweri Chamberlin, 1962 from Indonesia, L. arctus (Beier, 1967) from Papua New Guinea, L. subterraneus Mahnert, 2011 and L. microdentatus Mahnert, 2011 from Spain, and L. novaeguineae (Beier, 1965) from Indonesia and Papua New Guinea. The new species differs from L. johni by the absence of an epistome (a small rounded epistome is present in L. johni) and by the first two tergites with 2 setae each (4 setae each in L. johni), furthermore, L. johni has more teeth on the fixed chelal finger (19-20 vs. 15-16); it can be distinguished from $L$. roeweri by the presence of intercalary teeth on the chelal finger, which are lacking in $L$. roeweri; from $L$. arctus by its more robust chela (6.90-7.22 times as long as broad, as opposed to 8.30 times in $L$. arctus); from $L$. subterraneus by the latter having a more slender pedipalp femur (5.88-6.13 times as long as broad, compared to $7.30-7.45$ times in $L$. subterraneus) and by the fixed chelal finger with fewer teeth (15-16 vs. 26); from L. microdentatus by the presence of eyes; and from $L$. novaeguineae by the larger number spines on coxa II (10 vs. 5).

\subsection{Key to the Chinese species of Lagynochthonius}

1. Carapace with a distinct triangular epistome L. niger

- Carapace without epistome or with extremely indistinct epistome 2

2. Chelal fingers without intercalary teeth 3

- One or both chelal with intercalary teeth 5

3. Movable chelal finger more than 1.20 times longer than hand; movable finger with rounded vestigial teeth in basal half 4

- Movable chelal finger 0.97-1.00 times longer 
than hand; movable finger without vestigial teeth in basal half L. brachydigitatus $\mathbf{s p .} \mathbf{n}$.

4. Chelal hand 2.50-2.87 times as long as broad; $s b$ of movable finger 2 times as far from $s t$ as from $b$; tergites I-VII with 4 setae

\section{L. leptopalpus}

- Chelal hand 2.00 times as long as broad; $s b$ of movable finger 1.5 times as far from $s t$ as from $b$; only the tergites I-II with 4 setae $L$. sinensis

5. Only fixed chelal finger with intercalary teeth

L. harveyi

- Both chelal fingers with intercalary teeth 6

6. First two tergites with 2 setae; 4 corneate eyes; movable finger without vestigial teeth in basal half; movable chelal finger 1.00 times longer than hand

L. medog sp. $\mathbf{n}$.

- First two tergites with 4 setae; anterior pair of eyes well developed, posterior pair of eyes reduced to eyespots; movable finger with rounded vestigial teeth in basal half; movable chelal finger 1.20 times longer than hand

L. tonkinensis

Acknowledgements. We express our sincere thanks to Mark Harvey for reading and improving an early version of this manuscript. Helpful comments on the manuscript were also provided by an anonymous referee. We are grateful to Zhizhong Gao for collecting the specimens of $L$. medog. This work was supported by the National Natural Science Foundation of China (No. 31372154, 31093430) and, in part, by a Program of Ministry of Science and Technology of the Republic of China (2012FY110803) to Feng Zhang.

\section{References}

Beier, M. 1951: Die Pseudoscorpione Indochinas. — Mémoires du Muséum National d'Histoire Naturelle, Paris, nouvelle série 1: 47-123.

Beier, M. 1967: Pseudoscorpione vom kontinentalen Südost-Asien. - Pacific Insects 9: 341-369.

Chamberlin, J. C. 1929: A synoptic classification of the false scorpions or chela-spinners, with a report on a cosmopolitan collection of the same. Part 1. The Heterosphyronida (Chthoniidae) (Arachnida-Chelonethida). - Annals and Magazine of Natural History (10) 4: $50-80$.

Chamberlin, J. C. 1931: The arachnid order Chelonethida. - Stanford University Publications, Biological Sciences 7(1): 1-284.
Chamberlin, J. C. 1962: New and little-known false scorpions, principally from caves, belonging to the families Chthoniidae and Neobisiidae (Arachnida, Chelonethida). - Bulletin of the American Museum of Natural History 123: 303-352.

Edward, K. L. \& Harvey, M. S. 2008: Short-range endemism in hypogean environments: the pseudoscorpion genera Tyrannochthonius and Lagynochthonius (Pseudoscorpiones: Chthoniidae) in the semiarid zone of Western Australia. - Invertebrate Systematic 22: 259-293.

Harvey, M. S. 1988: Pseudoscorpions from the Krakatau Islands and adjacent regions, Indonesia (Chelicerata: Pseudoscorpionida). - Memoirs of the Museum of Victoria 49: 309-353.

Harvey, M. S. 1992: The phylogeny and classification of the Pseudoscorpionida (Chelicerata: Arachnida). Invertebrate Taxonomy 6: 1373-1435.

Harvey, M. S. 1999: The identity of the Indonesian pseudoscorpions Lagynochthonius johni (Redikorzev) and Lagynochthonius roeweri Chamberlin (Pseudoscorpiones: Chthoniidae). - Bulletin of the British Arachnological Society 11: 247-250.

Harvey, M. S. 2013: Pseudoscorpions of the World, version 3.0. Western Australian Museum, Perth. http://www.museum.wa.gov.au/catalogues-beta/pseudoscorpions. (Site visited on 20 March, 2014)

Hu, J. F. \& Zhang, F. 2012: New species of Lagynochthonius Beier (Pseudoscorpions: Chthoniidae) from Hainan island, China. - Entomological News 122(3): 223-232.

Hu, J. F. \& Zhang, F. 2012: A new species of Lagynochthonius (Pseudoscorpions: Chthoniidae) from Yunnan Province, China. - Acta Arachnologica 61(1): 2125.

Judson, M. L. I. 2007: A new and endangered species of the pseudoscorpion genus Lagynochthonius from a cave in Vietnam, with notes on chelal morphology and the composition of the Tyrannochthoniini (Arachnida, Chelonethi, Chthoniidae). - Zootaxa 1627: 53-68.

Mahnert, V. 2011: A nature's treasury: Pseudoscorpion diversity of the Canary Islands, with the description of nine new species (Pseudoscorpiones, Chthoniidae, Cheiridiidae) and new records. - Revista Ibérica de Aracnología 19: 27-45.

Muchmore, W. B. 1991: Pseudoscorpions from Florida and the Caribbean area. 14. New species of Tyrannochthonius and Lagynochthonius from caves in Jamacia [sic], with discussion of the genera (Chthoniidae). - Florida Entomologist 74: 110-121.

Vachon, M. 1941: Chthonius tetrachelatus P. (Pseudoscorpions) et ses formes immatures (1re note). - Bulletin du Muséum National d'Histoire Naturelle, Paris (2) 13: 442-449.

Redikorzev, V. 1922: Two new species of pseudoscorpion from Sumatra. — Ezhegodnik Zoologicheskago Muzeya 23: 545-554. 